\title{
Desenvolvimento intestinal de bezerros recém-nascidos aleitados com colostro de vacas tratadas com rbST ${ }^{1}$
}

\section{Adriana Regina Bagaldo ${ }^{2}$, Patricia Pauletti ${ }^{2}$, Eduardo Francisquine Delgado ${ }^{3}$, Dante Pazzanese Duarte Lanna ${ }^{3}$, Liris Kindlein ${ }^{4}$, Raul Machado Neto ${ }^{3}$}

\author{
1 Trabalho financiado pela FAPESP. \\ 2 Doutora, Depto. Zootecnia, ESALQ-USP, Av. Pádua Dias, 11, Caixa Postal 9, CEP: 13418-900 - Piracicaba, SP, Tel. (19) 3429 4260. \\ ${ }^{3}$ Depto. Zootecnia, ESALQ-USP, Av. Pádua Dias, 11, Caixa Postal 9, CEP: 13418-900 - Piracicaba, SP. \\ ${ }^{4}$ Doutoranda - Depto. Zootecnia ESALQ-USP, Av. Pádua Dias, 11, Caixa Postal 9, CEP: $13418-900$ - Piracicaba, SP.
}

RESUMO - Com o objetivo de avaliar o efeito de diferentes níveis de IGF-I sobre os indicadores de atividade celular hepática e intestinal em bezerros recém-nascidos, 42 vacas holandesas gestantes foram aleatoriamente distribuídas em dois grupos. O grupo rbST recebeu hormônio de crescimento (500 mg rbST) e o grupo controle recebeu injeção de vitamina E. As aplicações se iniciaram aos 35 dias pré-parto e foram repetidas a cada 14 dias até o parto. Os recém-nascidos foram distribuídos aleatoriamente nas seguintes idades de abate: após o nascimento e sem a ingestão de colostro; e 2 e 7 dias de vida com ingestão de colostro das respectivas mães. O delineamento experimental utilizado foi o inteiramente casualizado, em estrutura fatorial 2 x 3, correspondendo aos grupos das mães e às idades dos bezerros. Amostras do fígado, do jejuno e do íleo foram coletadas. Os bezerros do grupo rbST apresentaram, no jejuno, menores níveis de DNA e proteína aos 7 dias de vida, enquanto a concentração de proteína nesse grupo aumentou aos 2 dias de vida. Esse efeito também foi observado na relação proteína/RNA No grupo controle, o aumento de proteína foi verificado no 7으 dia. Os indicadores de atividade celular analisados sugerem que o IGF-I adicional no colostro de vacas tratadas com rbST teve participação na maturação celular intestinal dos bezerros, sendo determinante no comportamento da primeira geração de enterócitos.

Palavras-chave: atividade celular, bezerro, IGF-I, somatotropina, trato intestinal

\section{Intestinal development of new-born calves fed colostrum of cows treated with rbST}

\begin{abstract}
With the objective of evaluating different levels of IGF-I on the hepatical and intestinal indicators of cellular activity in newborn calves, 42 pregnant Holstein cows were randomly assigned to two groups: a) control: injection of vitamin $\mathrm{E}$ or b) rbST: injection of growth hormone (rbST). Injections started 35 days pre-partum and were repeated every 14 days until parturition. Newborn calves were randomly assigned to a $2 \times 3$ factorial arrangement of treatments (two mother groups and three different ages). After slaughter, samples from liver, jejunum and ileum were collected. Calves from rbST group showed lower levels of DNA and protein in jejunum at seven days of age, while protein concentration increased at two days of age. Similar response was observed for the ratio of protein/RNA in jejunum. In the control group, the increase in protein concentration was observed in the seventh day of age. The indicators of cellular activity measured in this trial suggested that greater IGF-I concentration in colostrum of rbST treated cows promoted intestinal cellular maturation by affecting behavior of first generation enterocytes.
\end{abstract}

Key Words: calf, cellular activity, IGF-I, intestinal tract, somatotropin

\section{Introdução}

O reconhecimento das razões imunológicas para o fornecimento de colostro a bezerros na fase neonatal é fato estabelecido. Na busca da base biológica para o diferencial de desempenho de recém-nascidos, verifica-se que o colostro, além de constituir-se fonte de nutrientes e de elementos de proteção, contém várias moléculas biologicamente ativas importantes para o crescimento e a sanidade animal. Entre os peptídeos bioativos presentes no colostro e no leite, destacam-se os fatores de crescimento semelhantes à insulina I e II (IGFs), que estimulam a mitogênese e a diferenciação celular (Odle et al., 1996).

A presença de IGF em altas concentrações no colostro é importante para o desenvolvimento do recém-nascido. Nas espécies bovinas, as concentrações de IGF-I são de 200 a 500 ng/mL no colostro e diminuem para 40 ng/mL do 
$6^{0}$ ao $15^{0}$ dia de lactação e para 0,0021 ng/mL aos 150-210 dias de lactação (Vacher et al., 1995; MacDonald, 1999).

Os efeitos biológicos dos IGFs presentes no colostro e no leite podem ser observados em inúmeros tecidos. Diversas evidências apontam para esta hipótese, por exemplo, a presença de receptores de IGF tipos I e II nas células epiteliais da glândula mamária e ao longo de todo o intestino do neonato, atuando no crescimento e na maturação do trato digestório durante o período pós-natal (Schober et al., 1990; LeRoith et al., 1994; Odle et al., 1996; Bühler et al., 1998; MacDonald, 1999). Pakkanen \& Aalto (1997) sugeriram que uma dieta rica em IGF-I, como o colostro, provoca aumento do crescimento e da taxa de renovação celular das células intestinais. Desse modo, contribui para um intestino funcionalmente mais eficiente, elevando o aproveitamento dos componentes da dieta, favorecendo processos anabólicos e estimulando o crescimento generalizado.

Os efeitos biológicos do IGF-I na secreção láctea de animais tratados com somatotropina bovina recombinante (rbST) (Hadsell et al., 1993) sobre os enterócitos e outros tecidos têm despertado questionamentos sobre a segurança do uso desse leite na dieta humana. O conhecimento da dinâmica intestinal do IGF-I pode contribuir para o entendimento de uma possível constituição do IGF-I das secreções lácteas sobre o crescimento dos enterócitos e de outros tecidos.

Este trabalho foi realizado com o objetivo de verificar o efeito de diferentes concentrações de IGF-I no colostro de vacas tratadas com rbST no período pré-parto sobre os indicadores de atividade celular intestinal e hepática de bezerros recém-nascidos.

\section{Material e Métodos}

Quarenta e duas vacas holandesas, multíparas, gestantes e com prenhez de macho confirmada por ultra-sonografia foram distribuídas ao acaso em dois grupos; os animais do grupo rbST receberam hormônio de crescimento durante o período seco, sem leite (500 mg rbST - somatotropina recombiante bovina - Boostin ${ }^{\circledR}$ ), e a partir dos 35 dias préparto, em intervalos de 14 dias (considerando a data prevista para a parição); e o grupo controle recebeu $2 \mathrm{~mL}$ de vitamina $\mathrm{E}$ (Monovin- $\mathrm{E}^{\circledR}$ - acetato de DL- $\alpha$-tocoferol $2 \mathrm{mg} / 20 \mathrm{~mL}$ ) nas mesmas datas de aplicação do hormônio. Optou-se pelo fornecimento de vitamina $\mathrm{E}$ aos animais do grupo controle pelo fato de o hormônio de crescimento adotado ter como excipiente a vitamina $\mathrm{E}$.

Os bezerros recém-nascidos, subdivididos segundo o grupo de suas mães, foram distribuídos ao acaso em três idades de abate: ao nascimento e sem a ingestão de colostro; às 48 (2 dias); e às 168 horas (7 dias) após o nascimento.

Os bezerros que não foram abatidos ao nascimento foram separados das mães e receberam colostro ( $5 \%$ do PV) proveniente de suas mães. Após a ingestão do colostro, os animais passaram a receber as próximas secreções lácteas da própria mãe, na quantidade de $4 \mathrm{~L}$, divididos em duas refeições diárias até a idade de abate.

Amostras do colostro foram coletadas e congeladas a $-20^{\circ} \mathrm{C}$ para análise de IGF-I. Ao abate, os animais foram anestesiados e exsangüinados e o fígado e os segmentos do jejuno e do íleo foram isolados para coleta de amostras. Os tecidos foram lavados com solução salina $(0,9 \% \mathrm{NaCl})$ e rapidamente congelados em nitrogênio líquido.

As concentrações de IGF-I no colostro foram analisadas por ensaio imunorradiométrico pós-extração, utilizando-se o kit DSL-5600 (Diagnostic Systems Laboratories, Inc.), e quantificadas em um contador gama.

A determinação de DNA total no jejuno, no íleo e no fígado foi feita de acordo com o método de Labarca \& Paigen (1980). A partir da extração do DNA, o RNA pôde ser separado, adicionando-se $3 \mathrm{~mL}$ de ácido perclórico 0,2 N. A solução foi lida em espectrofotômetro, a 260 e $280 \mathrm{~nm}$ (correção de proteína). A quantificação da proteína total foi determinada pelo método de Lowry et al. (1951).

Para todas as variáveis estudadas, foi utilizado o delineamento inteiramente casualizado, com os tratamentos dispostos em estrutura fatorial $2 \times 3$, correspondendo ao grupo da mãe (rbST ou controle) e às idades (ao nascimento, aos 2 ou 7 dias de idade).

Todos os dados foram submetidos à análise de variância pelo procedimento General Linear Model (PROC GLM) do programa estatístico SAS (1991). O teste Tukey foi aplicado para avaliação de diferenças entre médias de idade. Em caso de interação, os efeitos de grupo foram analisados dentro de cada idade, assim como as idades foram analisadas dentro de cada tratamento. Em todas as análises, adotou-se o nível de 5\% de significância.

\section{Resultados e Discussão}

O colostro de vacas tratadas com rbST durante o período em que não estavam em lactação apresentou valor de $874,53 \pm 335,02 \mathrm{ng} / \mathrm{mL}$ de IGF-I, enquanto o colostro daquelas do grupo controle apresentou concentração de IGF-I de 674,15 \pm 259,53 ng/mL $(\mathrm{P}<0,05)$. Portanto, os bezerros das vacas do grupo rbST ingeriram quantidade de IGF-I 30\% superior.

Na Tabela 1 constam as médias gerais das variáveis analisadas nos grupos rbST e controle e das idades e dos 
tecidos. Não foram verificados efeitos de interação (grupo $\times$ idade; $\mathrm{P}>0,05$ ). No íleo, a concentração de DNA aos 7 dias de vida foi maior que ao nascimento $(\mathrm{P}<0,05)$. No jejuno, houve efeito de interação grupo (controle ou rbST) $\times$ idade $(\mathrm{P}<0,05$, Figura 1). No segundo dia de vida, a concentração de DNA nos dois grupos foi maior $(5,5 \pm 1,1$ e 5,9 $\pm 0,8 \mathrm{mg} / \mathrm{g}$ tecido para controle e rbST, respectivamente) em comparação à concentração obtida ao nascimento (3,6 \pm 0,8 e 4,2 \pm 1,2 para controle e rbST, respectivamente). No sétimo dia de vida, o DNA no jejuno do grupo rbST (5,1 $\pm 1,1 \mathrm{mg} / \mathrm{g}$ tecido) não diferiu da concentração encontrada ao nascimento. No grupo controle, a concentração de DNA $(6,41 \pm 0,98 \mathrm{mg} / \mathrm{g}$ tecido) nessa idade foi maior que ao nascimento e, ainda, superior à do grupo rbST aos 7 dias de idade. A concentração de DNA no fígado não sofreu efeito dos tratamentos (Tabela 1).

No jejuno e no fígado aos 2 dias de vida, a concentração de RNA foi maior $(\mathrm{P}<0,05)$ em comparação à obtida ao nascimento (Tabela 1). No íleo, essa diferença ocorreu quando os bezerros estavam com 7 dias de vida $(\mathrm{P}<0,05)$.

A concentração de proteína total no jejuno foi influenciada pela interação grupo $\times$ idade $(\mathrm{P}<0,05$; Figura 2). Nos bezerros do grupo rbST, a concentração de proteína foi maior no segundo dia de vida (121,3 $\pm 38,1 \mathrm{mg} / \mathrm{g}$ tecido) em comparação à registrada ao nascimento $(90,6 \pm 21,5 \mathrm{mg} / \mathrm{g}$ tecido) e aos 7 dias de vida (79,7 $\pm 10,0 \mathrm{mg} / \mathrm{g}$ tecido). No grupo controle, o aumento na concentração de proteína foi verificado apenas no sétimo dia (95,4 \pm 26,6, 98,6 $\pm 21,8$ e 123,7 $\pm 24,2 \mathrm{mg} / \mathrm{g}$ tecido ao nascimento, aos 2 e aos 7 dias de vida, respectivamente). $\mathrm{O}$ grupo controle também apresentou maior concentração de proteína aos 7 dias em comparação ao grupo rbST. No fígado, a concentração de proteína nos bezerros com 2 dias de vida foi maior que a obtida nos recém-nascidos $(\mathrm{P}<0,05$, Tabela 1$)$.

A quantidade de proteína por célula, verificada pela relação proteína/DNA, não comprovou efeito de interação,

Tabela 1 - Concentrações de DNA, RNA e proteína no fígado, no jejuno e no íleo dos bezerros dos grupos controle e rbST em três idades Table 1 - DNA, RNA and protein concentrations in the liver, jejunum and ileum of calves from control or rbST groups and three different ages

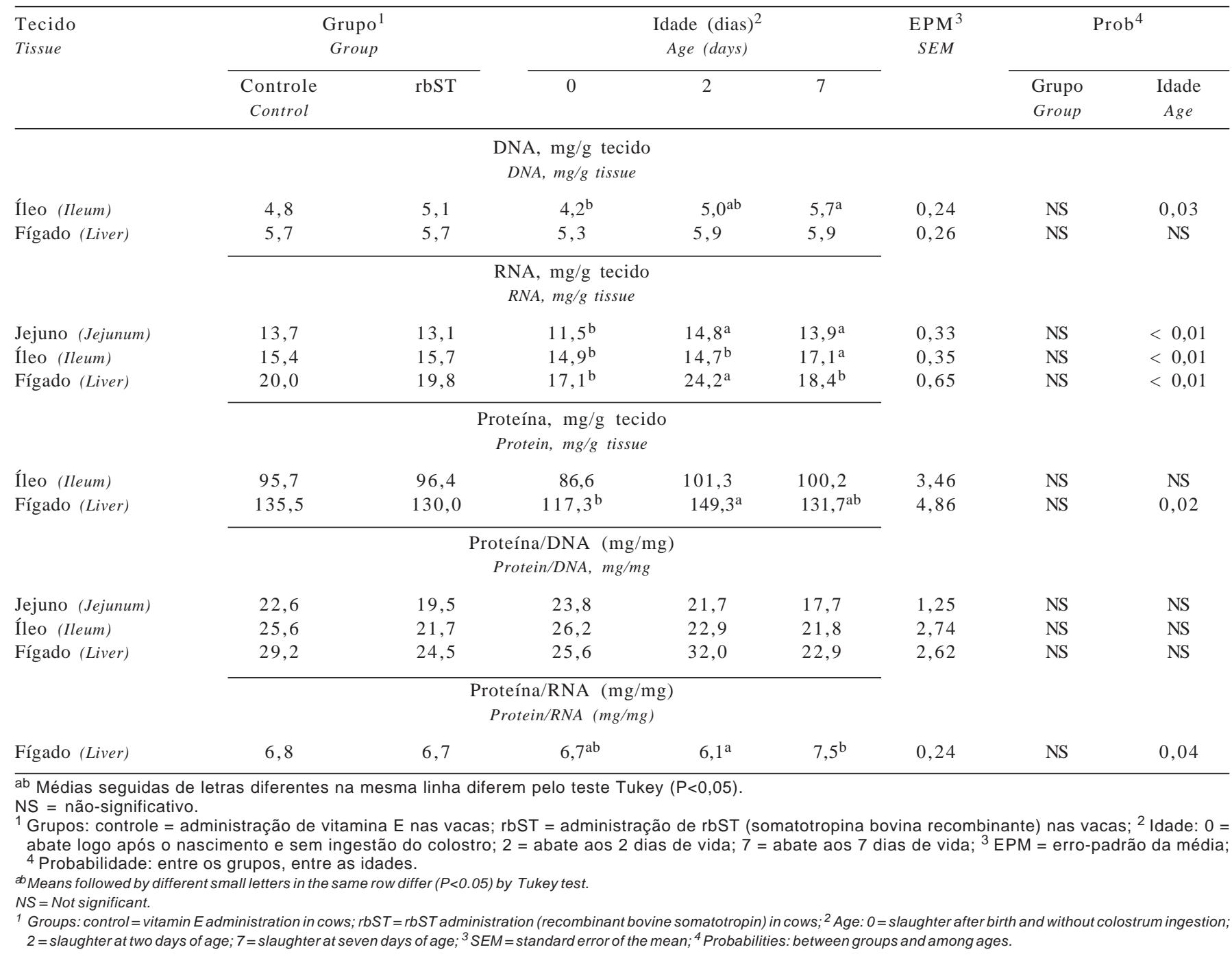




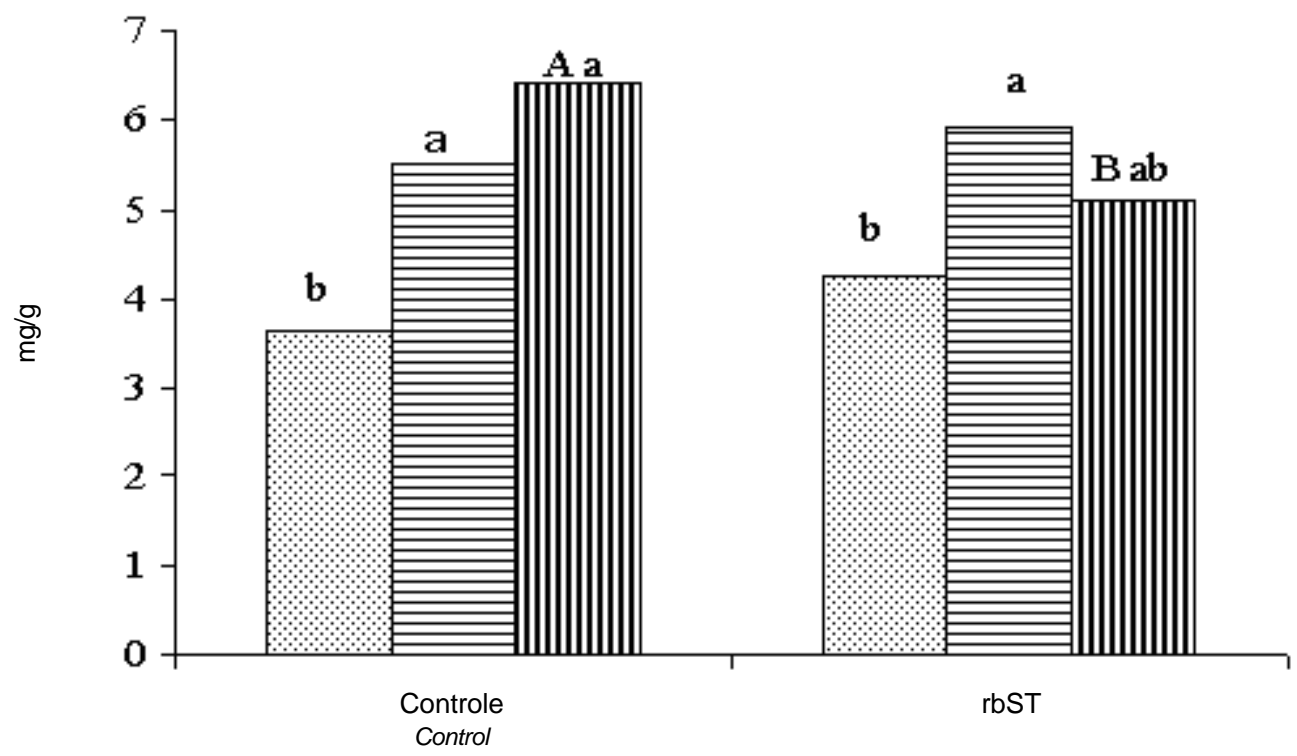

E nascimento/hirth 12 das'days 07 das'days

\footnotetext{
ab Médias seguidas de letras diferentes, dentro de cada grupo, diferem $(P<0,05)$ pelo teste Tukey.

${ }^{A B}$ Médias seguidas de letras diferentes, dentro da mesma idade, diferem $(P<0,05)$ pelo teste $F$

ab Means followed by different letter, in each group, differ $(P<0.05)$ by Tukey test.

$A B$ Means followed by different letter, in the same age, differ $(P<0.05)$ by $F$ test.
}

Figura 1 - Concentrações de DNA total (mg/g tecido) no jejuno de bezerros que receberam colostro de vacas tratadas ou não com rbST. Figure 1 - Total DNA concentration ( $\mathrm{mg} / \mathrm{g}$ tissue) in the jejunum of calves that received colostrum from control or rbST treated cows.

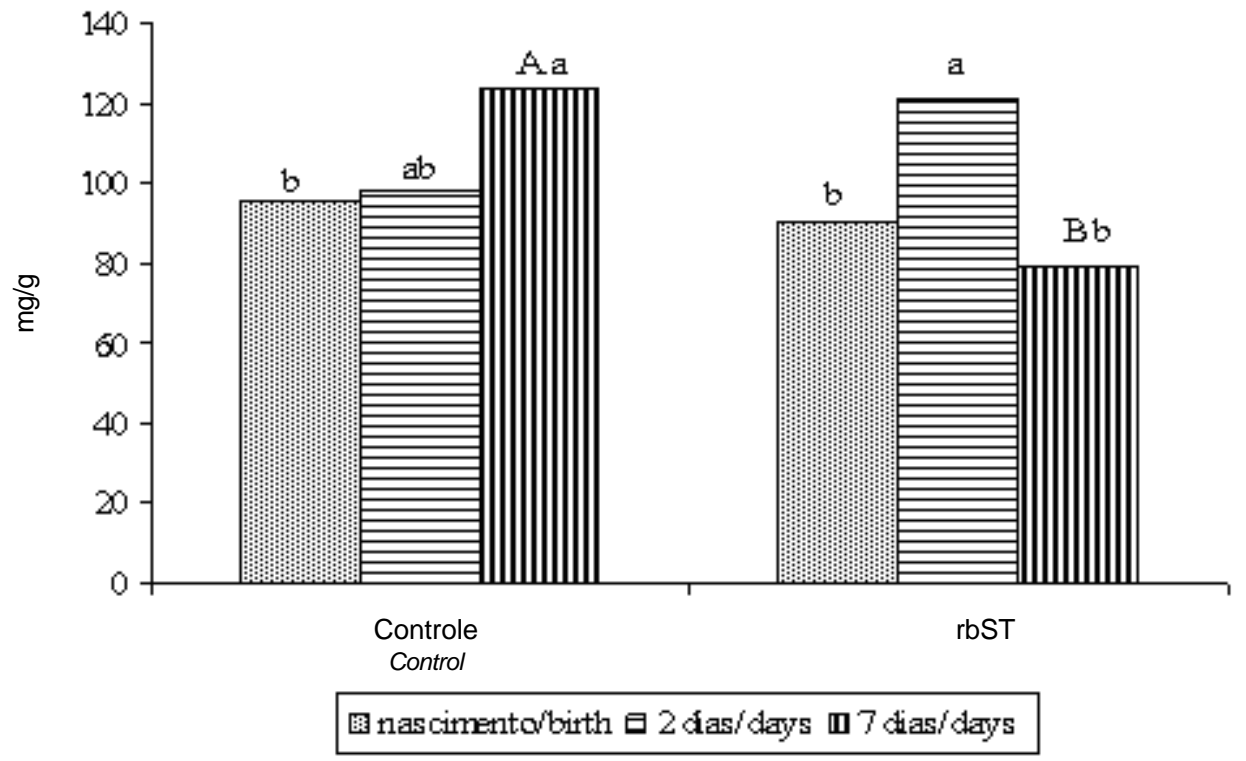

\footnotetext{
ab Médias seguidas de letras diferentes, dentro de cada grupo, diferem $(P<0,05)$ pelo teste Tukey.

$A B$ Médias seguidas de letras diferentes, dentro da mesma idade, diferem $(P<0,05)$ entre si pelo teste $F$.

ab Means followed by different letter, in each group, differ $(P<0.05)$ by Tukey test.
}

$A B$ Means followed by different letter, in the same age, differ $(P<0.05)$ by $F$ test.

Figura 2 - Concentrações de proteína (g/mg tecido) no jejuno de bezerros que receberam colostro de vacas tratadas ou não com rbST. Figure 2 - Protein concentrations ( $\mathrm{g} / \mathrm{mg}$ tissue) in the jejunum of calves that received colostrum from control or rbST treated cows. 
nem diferenças, entre os grupos ou idade nos três tecidos analisados (Tabela 1).

A interação grupo $\times$ idade influenciou $(\mathrm{P}<0,05)$ a atividade de tradução, pela relação proteína:RNA, no jejuno e íleo (Figuras 3 e 4). No jejuno dos bezerros do grupo rbST, a atividade de tradução aumentou do nascimento (7,79 $\pm 1,34$ mg proteína/mg RNA; Figura 3) ao segundo dia (8,58 $\pm 3,40$ mg proteína/mg RNA) e diminuiu aos 7 dias de idade $(6,03 \pm 0,75)$, enquanto, no grupo controle, não houve diferença entre as idades $(8,42 \pm 2,56,6,56 \pm 2,22$ e 8,49 \pm 1,55 mg proteína/mg RNA ao nascimento, aos 2 e aos 7 dias de idade, respectivamente). Entretanto, o grupo controle apresentou maior atividade de tradução aos 7 dias de vida em comparação ao grupo rbST nessa mesma idade.

No íleo, o perfil da atividade de tradução foi semelhante ao verificado no jejuno (Figura 4). No grupo controle, não houve diferença entre as idades $(5,1 \pm 1,3,6,1 \pm 0,9,6,4 \pm 1,7 \mathrm{mg}$ proteína/mg RNA, ao nascimento e aos 2 e aos 7 dias de vida, respectivamente). No grupo rbST, a atividade de tradução aumentou do nascimento (5,8 \pm 1,2 mg proteína/mg RNA) ao segundo dia (7,6 $\pm 1,2 \mathrm{mg}$ proteína/mg RNA) e diminuiu no sétimo dia de vida (5,3 \pm 1,2 mg proteína/mg RNA).

A atividade de tradução no fígado não sofreu efeito dos grupos, mas, entre as idades avaliadas, foi maior aos 7 dias de vida, em comparação aos 2 dias, e não diferiu da atividade determinada ao nascimento (Tabela 1 ).
Entre os indicadores de atividade celular analisados, não foram observadas diferenças entre os grupos logo após o nascimento, o que sugere que a administração de rbST nas mães não teve efeito sobre essas variáveis durante o desenvolvimento fetal. Esse resultado reflete também que os efeitos observados nas outras idades decorreram da presença do IGF-I no trato intestinal.

Uma das características do final da permeabilidade intestinal, quando finaliza a transferência de macromoléculas da luz do intestino para o sistema circulatório de ruminantes recém-nascidos, é a presença de enterócitos em diferentes estádios de maturação (Jochims et al., 1994). Neste estudo, as concentrações de DNA no jejuno dos animais do grupo controle aumentaram no segundo dia de vida, um indicativo da condição de transição de geração de células epiteliais intestinais. Esse aumento de DNA indica um processo proliferativo determinante da hiperplasia da mucosa intestinal. Nesse mesmo período, Bessi et al. (2002) encontraram a primeira e a segunda população celular, sugerindo uma relação estreita entre a troca e a proliferação de células com o final do processo.

Também no grupo controle, os níveis de proteína (Figura 2) não aumentaram aos 2 dias de vida, indicando que, como houve renovação celular, a nova população de células ainda não estava madura, ou seja, as células estariam em um estádio intermediário de síntese de proteína. A

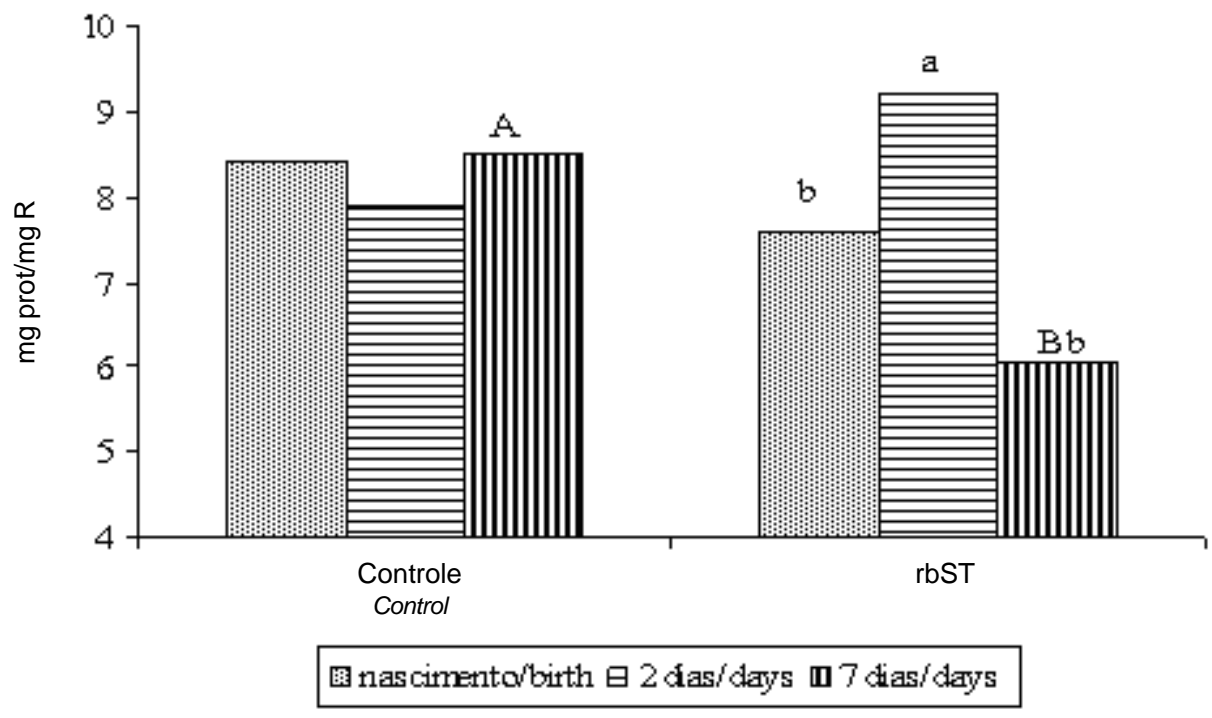

\footnotetext{
ab Médias seguidas de letras diferentes, dentro de cada grupo, diferem $(P<0,05)$ pelo teste Tukey.

$A B$ Médias seguidas de letras diferentes, dentro da mesma idade, diferem $(P<0,05)$ pelo teste $F$.

ab Means followed by different letter, in each group, differ $(P<0.05)$ by Tukey test.

$A B$ Means followed by different letter, in the same age, differ $(P<0.05)$ by $F$ test.
}

Figura 3 - Relação proteína/RNA (mg proteína/mg RNA) no jejuno de bezerros que receberam colostro de vacas tratadas ou não com rbST.

Figure 3 - Protein/RNA ratio ( $m g$ protein/mg RNA) in the jejunum of calves that received colostrum from control or rbST treated cows. 


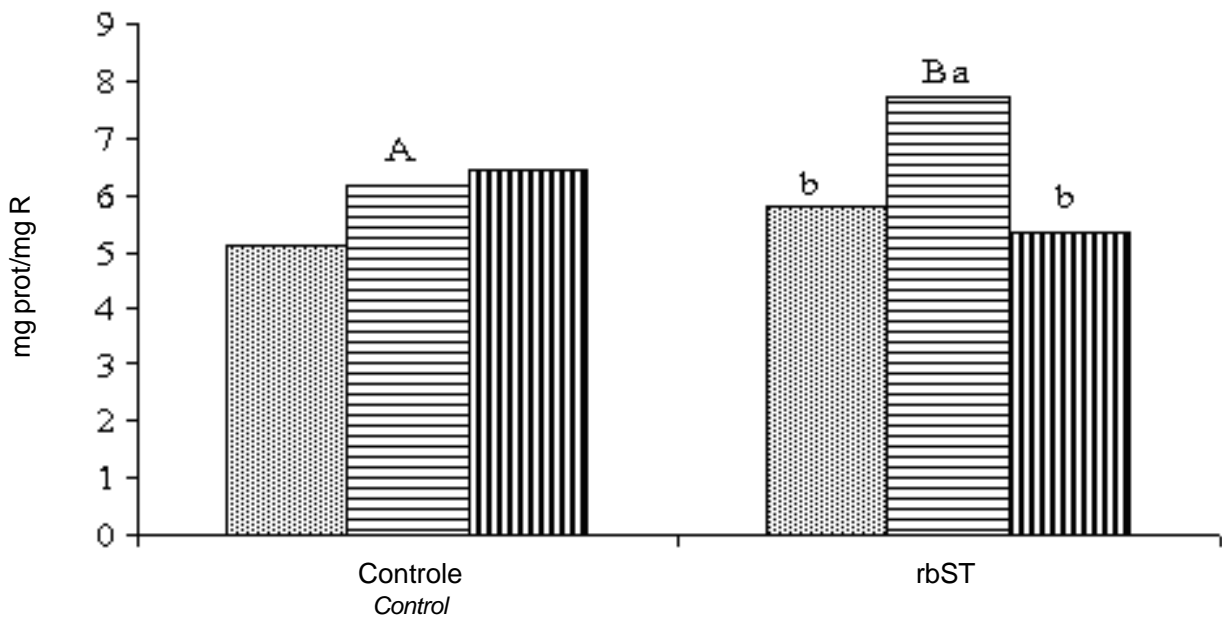

涪 nascimento/birth $日 2$ das/days $\mathbf{0} 7$ dias/days

\footnotetext{
ab Médias seguidas de letras diferentes dentro de cada tratamento diferem $(P<0,05)$ pelo teste Tukey.

$A B$ Médias seguidas de letras diferentes na mesma idade diferem $(P<0,05)$ pelo teste $F$.

ab Means followed by different letter, in each group, differ $(P<0.05)$ by Tukey test.

$A B$ Means followed by different letter, in the same age, differ $(P<0.05)$ by $F$ test.
}

Figura 4 - Relação proteína/RNA (mg proteína/mg RNA) no íleo de bezerros que receberam colostro de vacas tratadas ou não com rbST. Figure 4 - Protein/RNA ratio ( $m g$ protein/mg RNA) in the ileum of calves that received colostrum from control or rbST treated cows.

resposta caracterizando a maturidade celular pôde ser observada aos 7 dias de vida com o aumento da concentração de proteína. Durante os 7 dias de vida, a atividade de tradução manteve-se constante. Todas essas observações encontradas no grupo controle estão relacionadas às atividades de proliferação celular e apoptose (Smeaton \& Simpson, 1985).

O fornecimento de colostro de vacas tratadas com rbST pode ter determinado as alterações na mucosa intestinal dos bezerros deste grupo. Nesse grupo (Figura 1), a concentração de DNA aos 2 dias de vida aumentou, refletindo a proliferação celular no período. Entretanto, aos 7 dias de vida, o DNA reduziu para níveis intermediários, em comparação ao nascimento e aos 2 dias de vida. Uma das causas para essa observação seria a relação entre taxa de proliferação celular e apoptose inferiores.

A concentração de proteína do grupo controle aumentou apenas no sétimo dia de vida dos bezerros (Figura 2). No grupo rbST, no entanto, houve aumento de proteína no segundo dia de vida. Esse resultado, relacionado ao obtido na concentração de DNA, que não aumentou aos 2 dias de vida, sugere um comportamento de célula mais madura, acompanhado da diminuição da apoptose, que, por sua vez, está relacionada à degradação protéica, aumentando a meia-vida dos enterócitos e, conseqüentemente, acarretando o acúmulo da proteína na mucosa. Outra possibilidade de contribuição para esse acúmulo de proteína estaria relacionada à maior atividade de enzimas digestivas no epitélio intestinal. Bessi et al. (2002) observaram reação de enzima fosfatase ácida, que indica a presença de enzimas hidrolíticas nas membranas apicais das células e reação em lisossomos no jejuno de bezerros aos três dias de vida, reação não observada ao nascimento e após a ingestão do colostro.

No sétimo dia de vida, a população celular madura pode estar entrando em processo apoptótico, causando diminuição na síntese protéica na mucosa do jejuno. Essas mudanças também refletiram na atividade de tradução (proteína/RNA), que foi maior no segundo dia e se igualou aos níveis iniciais no sétimo dia, sugerindo, novamente, maturidade da competência absortiva das células.

Essas variáveis, quando analisadas isoladamente dentro de cada idade, podem justificar as inferências propostas. As concentrações de DNA e proteína e a atividade de tradução no grupo rbST foram menores que no grupo controle aos 7 dias de vida, confirmando a hipótese de diminuição da apoptose, pois as células estariam iniciando o processo de degradação de DNA e proteínas, ao passo que, no grupo controle, já se encontraria nova geração de células, com população mais madura que a anterior.

Segundo Rauprich et al. (2000), o aumento da concentração do DNA no intestino de recém-nascidos tem forte relação 
com a presença de peptídios bioativos presentes no colostro. No entanto, nem todos os pesquisadores obtiveram respostas positivas em relação à concentração de DNA no intestino de animais que receberam colostro. Com esse fato, novo papel (reduzir a apoptose) tem sido sugerido ao IGF-I(Blättler et al., 2001), sugerindo que o mesmo ocorreu com os animais que ingeriram colostro de vacas tratadas com rbST, visto que a concentração de DNA no jejuno aos 7 dias de vida foi menor que a obtida nos animais do grupo controle.

As respostas encontradas neste trabalho estão de acordo com as observações de Winesett et al. (1995), que relataram que a presença de nutrientes no trato pode alterar a taxa de renovação celular, e de Potten et al. (1997), que afirmaram que, além da proliferação celular, a apoptose também é um regulador do número de células e pode ser inibida pela presença do IGF-I. Além disso, estudos têm comprovado que a administração do IGF-I simultaneamente com a nutrição parenteral total (NPT) pode prevenir ou reverter a atrofia da mucosa, por estimular a proliferação dos enterócitos e a diminuição da apoptose, mantendo a integridade do tecido (Peterson et al., 1997; Dahly et al., 2002).

Resultados semelhantes aos registrados neste estudo foram encontrados por Blättler et al. (2001), que verificaram que, prolongando o consumo de colostro, a concentração de DNA não foi afetada e houve aumento na proteína, sugerindo redução da apoptose. Respostas semelhantes também foram observadas por Mylonas et al. (2000) e Playford et al. (2000).

Neste estudo, não foi observada maior proliferação celular nos animais tratados com rbST. Provavelmente, a quantidade de IGF-I ingerida por esse grupo não foi suficiente para aumentar a proliferação celular da mucosa intestinal. Segundo Ma \& Xu (1997), a ingestão de IGF-I em baixas concentrações estimula a maturação das células epiteliais, enquanto quantidades elevadas são necessárias para estimular o crescimento intestinal.

Segundo Patureau-Mirand et al. (1990), o aumento do conteúdo de proteína total no intestino em resposta à ingestão de colostro resulta de aumento da síntese endógena e da absorção de proteína do colostro. Análises de regressão também indicaram correlação positiva entre o consumo de proteína e a taxa de síntese de proteína no fígado. Sob essa hipótese, recém-nascidos que ingerem colostro consomem mais proteína e, portanto, absorvem mais aminoácidos, que ficam disponíveis para síntese protéica, especialmente no intestino e no fígado (Burrin et al., 1992). Essas condições também foram verificadas neste trabalho e indicam que o fornecimento do colostro, independentemente do tratamento, aumentou a concentração de proteína aos 2 dias de vida (Tabela 1).
Nesta pesquisa, as concentrações de DNA e RNA (mg/g de tecido) no jejuno e no íleo aumentaram com a idade e a concentração de proteína aumentou no fígado e no jejuno $(\mathrm{P}<0,05$, Tabela 1$)$. Diferentes padrões relacionados à idade e ao aumento de DNA eram esperados nos dois segmentos intestinais, caracterizando diferenças espaciais e temporais nas taxas de proliferação dos enterócitos durante as primeiras 48 horas de vida.

\section{Conclusões}

As respostas dos indicadores de atividade celular intestinal e hepática de bezerros que receberam colostro de vacas tratadas com rbST sugerem que o IGF-I teve importante participação na maturação celular e papel determinante no comportamento da primeira geração de enterócitos. Outro aspecto significativo nesse processo é o nível de IGF-I, que pode definir diferentes respostas na maturação e na proliferação celular. Entretanto, mais estudos são necessários para observação dessas respostas em período mais prolongado.

\section{Agradecimento}

À Fapesp, pela concessão do auxílio à pesquisa.

\section{Literatura Citada}

BESSI, R.; PAUletTi, P.; d’ARCE, R.D. et al. Absorção de anticorpos do colostro em bezerros. I. Estudo no intestino delgado proximal. Revista Brasileira de Zootecnia, v.31, n.6, p.2314-2324, 2002.

BLÄTTLER, U.; HAMMON, H.M.; MOREL, C. et al. Feeding colostrum, its composition and feeding duration variably modify proliferation and morphology of the intestine and digestive enzyme activities of neonatal calves. Journal of Nutrition, v.131, n.4, p.1256-1263, 2001

BÜHLER, C.; HAMMON, H.; ROSSI, G.L. et al. Small intestinal morphology in eight-day-old calves fed colostrum for different durations or only milk replacer and treated with Long-R3-insulin growth factor I and growth hormone. Journal of Animal Science, v.76, n.3, p.758-765, 1998.

BURRIN, D.G.; SHULMAN, R.J.; REEDS, P.J. et al. Porcine colostrum and milk stimulate visceral organ and skeletal muscle protein synthesis in neonatal piglets. Journal of Nutrition, v.122, n.6, p.1205-1213, 1992.

DAHLY, E.M.; GUO, Z.W.; NEY, D.M. Alterations in enterocyte proliferation and apoptosis accompany TPN-induced mucosal hypoplasia and IGF-I-induced hyperplasia in rats. Journal of Nutrition, v.132, n.7, p.2010-2014, 2002.

HADSELL, D.L.; BAUMRUCKER, C.R.; KESINGER, R.S. Effects of elevated blood insulin-like growth factor-i (IGF-I) concentration upon IGF-I in bovine mammary secretions during the colostrum phase. Journal of Endocrinology, v.137, p.223-230, 1993.

JOCHIMS, K.; KAUP, F.J.; DROMMER, W. Immunoelectron microscopic demonstration of the absorption of colostral igg by small-intestinal enterocytes in newborn rats. Research in Veterinary Science, v.57, n.1, p.146-151, 1994. 
LABARCA, C.; PAIGEN, K. A simple, rapid, and sensitive DNA assay procedure. Analytical Biochemistry, v.102, n.2, p.344-352, 1980.

LeROITH, D.; SAMPSON, P.C.; ROBERTS, C.T. How does the mitogenic insulin-like growth factor I receptor differ from the metabolic insulin receptor? Hormone Research, v.41, p.7479 (suppl. 2), 1994.

LOWRY, O.H.; ROSENBROUGH, N.J.; FARR, A.L. et al. Protein measurement with folin phenol reagent. Journal of Biological Chemistry, v.193, n.2, p.265-275,1951.

MA, L.; XU, R.J. Oral insulin-like growth factors-I stimulates intestinal enzyme maturation in newborn rats. Life Sciences, v.61, n.1, p.51-58, 1997.

MACDONALD, R.S. The role of insulin-like growth factors in small intestinal cell growth and development. Hormone Metabolism Research, v.31, n.2/3, p.103-113, 1999.

MYLONAS, P.G.; MATSOUKA, P.T.; PAPANDONIOU, E.V. et al. Growth hormone and insulin-like growth factor I protect intestinal cells from radiation induced apoptosis. Molecular and Cellular Endocrinology, v.160, n.1, p.115-122, 2000.

ODLE, J.; ZIJLSTRA, R.T.; DONOVAN, S.M. Intestinal effects of milkborne growth factors in neonates of agricultural importance. Journal of Animal Science, v.74, n.10, p.2509-2522, 1996.

PAKKANEN, R.; AALTO, J. Growth factors and antimicrobial factors of bovine colostrum. International Dairy Journal, v.7, n.3, p.285-297, 1997.

PATUREAU-MIRAND, P.; MOSONI, L.; LEVEUX, D. et al. Effect of colostrum feeding on protein metabolism in the small intestine of newborn lambs. Biology of Neonate, v.57, n.1, p.30-36, 1990

PETERSON, C.A.; CAREY, H.V.; HINTON, P.L. et al. GH elevates serum IGF-I levels but does not alter mucosal atrophy in parenterally fed rats. American Journal of PhysiologyGastrointestinal and Liver Physiology, v.272, n.5, p.G1100G1108, 1997.
PLAYFORD, R.J.; MACDONALD, C.E.; JOHNSON, W.S Colostrum and milk-derived peptide growth factors for the treatment of gastrointestinal disorders. American Journal of Clinical Nutrition, v.72, p.5-14, 2000.

POTTEN, C.S.; BOOTH, C.; PRITCHARD, D.M. The intestinal epithelial stem cell: the mucosal governor. International Journal of Experimental Pathology, v.78, n.4, p.219-243, 1997.

RAUPRICH, A.B.E.; HAMMON, H.M.; BLUM, J.W. Influence of feeding different amounts of first colostrum on metabolic, endocrine, and health status and on growth performance in neonatal calves. Journal of Animal Science, v.78, n.4, p.896908, 2000.

STATISTICAL ANALYSIS SYSTEM - SAS. SAS/STAT: user's guide. release 6.08 Cary: 1991. 1028p.

SCHOBER, D.A.; SIMMEN, F.A.; HADSELL, D.L. et al. Perinatal expression of type I IGF receptors in porcine small intestine. Endocrinology, v.126, n.2, p.1125-1132, 1990.

SMEATON, T.C.; SIMPSON, M.W. Epithelial cell renewal and antibody transfer in the intestine of the fetal and neonatal lamb. Australian Journal of Experimental Biological Science, v.63, n.1, p.41-51, 1985.

VACHER, P.Y.; BESTETTI, G.; BLUM, J.W. Insulin-like growth factor I absorption in the jejunum of neonatal calves. Biology of the Neonate, v.68, n.5, p.354-367, 1995.

WINESETT, D.E.; ULSHEN, M.H.; HOYT, E.C. et al. Regulation and localization of the insulin-like growth factor system in small bowel during altered nutrient status. American Journal of Physiology - Gastrointestinal and Liver Physiology, v.268, n.4, p.G631-G640, 1995. 